\title{
CIF President Presents Statement to the Forest Sector Advisory Council, Montreal, Quebec, February 1, 1994
}

To: Federal Ministers: Hon. John Manley, Minister of Industry, Science \& Technology, and Hon. Anne McLellan, Minister of Natural Resources

I support what my industry and labor colleagues have presented. However, there are a few forest-related concerns on which I would like to elaborate. The importance of the forest products industry to our national economy has been well described. At the same time, we must remember that forest health is basic to the long-term health of the forest products industry. We can compete in this respect as well.

The National Forest Strategy is a significant document, and represents a major cooperative effort within the forestry community - a "Team Canada" approach as described by Mike Apsey. We have come a long way together in improving forestry practice. It is significant to note that both industry and labor have responded well to their commitments in the National Forest Strategy. The federal government also has a major role to play in the strategy, besides its national and international responsibilities.

Robert Findley commented in his presentation that we need a science base for sustainable forestry. There are two major needs in this regard.

1. Improved inventories of the forest are needed to provide a scientific base of facts in order to plan for sustainability. There is concern about the reliability of our growth and yield data which are essential for reasoned calculation of allowable cuts. In addition, in recognition of society's increased demands and the need for more sophisticated management, we need to expand the inventories to include plants, animals, habitat, and the ecological characteristics of the land. This is essential for developing more site-specific treatments and improved, more comprehensive planning.

2. Research on the forest itself - particularly more work on basic ecosystem processes, and the high-technology applications to understanding and managing the forest. Frank Dottori described industry successes in research on the product and engineering aspects through industry involvement. Such models have not yet been applied to research on the forest itself, and we are looking into a possible way to get more industry participation in and support of forest-related research.

This leads to two specific requests to your government:

1. Continued support of the Canadian Forestry Service. The CFS plays an essential role in national and international forestry affairs and representations. As well, it is our single most important forest research agency, and the only one with a national approach to forest-related problems. It is important that this organization be maintained at an effective level to fulfill its mandate, and to meet its commitments under the National Forest Strategy.

2. To ensure the continuity of the federal-provincial forestry agreements. These have provided an important level of support to improve forestry practices, and have proven to be an important level of support to improve forestry practices, and have proven to be an important and catalytic way to developing partnerships and cooperative activities. We suggest that needs of inventory and research may also be well addressed through this means.

\section{Moncton and New Brunswick Gold Medal Awards Presented at SYLVICON'94}

Francois Levesque of Université de Moncton, second from left and Luc Poulin of University of New Brunswick, second from right, received CIF gold medals during SYLVICON '94 from Ted Needham, chairman of Maritime Section, left, and Peter Murphy, president, right.

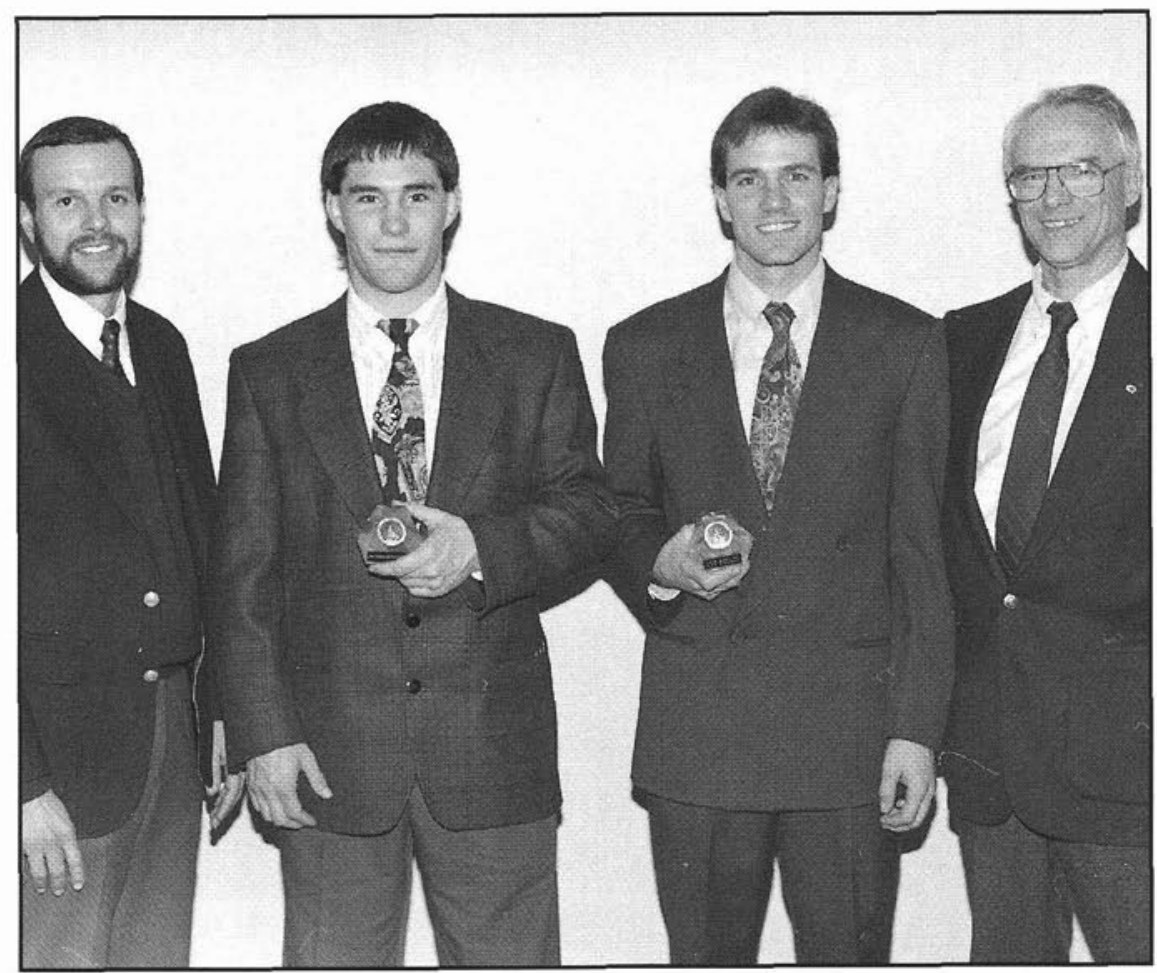

